\title{
Evaluation of ThinkFirst for Kids Injury Prevention Curriculum for Grades 7/8
}

\author{
Michael Vassilyadi, Cheryll Duquette, Mohammed F. Shamji, Shari Orders, \\ Simon Dagenais
}

\begin{abstract}
Background: Head injury causes substantial morbidity and mortality in children. The ThinkFirst For Kids (TFFK) program improves knowledge of safe behaviours in kindergarten to Grade 6 students. Methods: This study evaluated the TFFK curriculum for grade 7/8 students. Knowledge acquisition was assessed quantitatively by an injury prevention test at baseline, at curriculum completion, and six weeks later. Participant experiences and behaviours were explored qualitatively by interviews and focus groups. Results: Students $(n=204)$ and teachers $(n=6)$ from four schools participated in this study. Test scores improved from baseline $(26.48 \pm 0.17, n=204)$, to completion $(27.75 \pm 0.16, \mathrm{n}=176)$, to six weeks post-completion $(28.65 \pm 0.13, \mathrm{n}=111)(\mathrm{p}<0.05)$. Most students reported their decision-making and participation in risky behaviors was altered by the curriculum. Interpretation: The TFFK curriculum may promote education about head injury prevention among Grade 7/8 students, with a suggestion of long-term knowledge retention. The curriculum was wellreceived and may be suitable to reduce risky behavior and injuries in children.
\end{abstract}

RÉSUMÉ: Évaluation du programme « Pensez d'abord les enfants » pour la prévention des blessures chez les étudiants de 7e et 8e année. Contexte: Les blessures à la tête sont responsables d'une morbidité et d'une mortalité importantes chez les enfants. Le programme « Pensez d'abord les enfants » (PAE) améliore la connaissance des comportements sécuritaires chez les enfants de la maternelle à la 6e année. Méthodes : Le but de l'étude était d'évaluer le PAE chez les étudiants de 7e et de 8e année. L'acquisition des connaissances a été évaluée quantitativement au moyen d'un test portant sur la prévention des blessures au début, à la fin du programme et 6 semaines plus tard. Les expériences et les comportements des participants ont été examinés quantitativement par des entrevues et des groupes de discussion. Résultats : Les étudiants $(n=204)$ et les professeurs $(n=6)$ de 4 écoles ont participé à l'étude. Les scores des tests à la fin du programme $(27,75 \pm 0,16 ; n=176)$ et 6 semaines plus tard $(28,65$ $\pm 0,13 ; \mathrm{n}=111)$ se sont améliorés par rapport aux scores obtenus avant le début de l'enseignement $(26,48 \pm 0,17 ; \mathrm{n}$ $=204 ; \mathrm{p}>0,05)$. La plupart des étudiants ont rapporté que leur prise de décision et leur participation à des comportements à risque avait été modifiée par le programme. Interprétation : Selon les résultats de notre étude, le PAE peut favoriser l'enseignement de la prévention des blessures à la tête chez les étudiants de 7e et $8 \mathrm{e}$ année et il pourrait y avoir persistance des connaissances acquises à long terme. Le cours a été bien accueilli et pourrait être approprié pour diminuer les comportements à risque et les blessures chez les enfants.

Can. J. Neurol. Sci. 2009; 36: 761-768

Accidental injuries are often preventable with specific education programs offering an effective and relatively inexpensive means of reducing such injury among children. Interventions promoting bicycle safety typically include community education, school education, helmet giveaway or discount sales programs, and legislation requiring bicycle helmet use. Such programs have been demonstrated to increase the use of bicycle helmets among children in kindergarten to Grade $6 .{ }^{1-3}$ Educational programs have also been linked to a reduction in bicycle-related injuries among 5-14 year-old children., Translation of such knowledge and behavior into actual decreases in injury is ambiguous and challenging to investigate, but nevertheless numbers of cycling-related head-injury admissions to hospitals dropping between 1994-1995 and 2003-

From the Division of Neurosurgery (MV), Children's Hospital of Eastern Ontario; Division of Neurosurgery (MV, MFS), The Ottawa Hospital; Faculty of Education (CD, SO), Faculty of Medicine (MV, SD), University of Ottawa, ON, Canada. Received May 13, 2009. Final Revisions Submitted June 24, 2009 Correspondence to: Michael Vassilyadi, The Children's Hospital of Eastern Ontario, Division of Neurosurgery, 401 Smyth Road, Ottawa, Ontario, K1H 8L1, Canada. 
2004 , the largest decrease of $64 \%$ experienced in the 5-9 year age range. ${ }^{6}$

Other interventions that promote a broader message of injury prevention and are exclusively school-based lead to gains in knowledge and positive behaviour changes among students in Grades 1-5. ${ }^{7}$ The ThinkFirst For Kids (TFFK) program is based on children understanding the importance of their brain and spinal cord and the fragility of those structures so that they make the safe choice to protect themselves from long-term injury. A curriculum for young students in junior kindergarten through Grade 6 is based on current applied-learning and behavioural theories contending that varied messages delivered over time will increase understanding and knowledge retention, resulting in sustained learned behaviour. ${ }^{8}$ Research on the ThinkFirst for Kids program showed that students in Grades 1, 2, and 3 lack basic knowledge regarding safety and in selecting against highrisk injury behaviours. ${ }^{9,10}$ A focused curriculum resulted in increased knowledge about the prevention of traumatic nervous system injury, with greatest score improvement among lower socioeconomic status schools, ${ }^{10}$ alongside decreases in selfreported, high-risk behaviours. ${ }^{11}$ Similar knowledge transfer results were seen with such intervention for Grade 6 and 7 students, although those evaluations included self-report questionnaire instead of specific summative evaluation, and no evaluation was performed to evaluate long-term knowledge retention. $^{12}$

Other successful interventions include school visits, parental involvement, teacher awareness and use of prevention strategies, school and community attributes, child behaviours, peer relationships, and supervision. ${ }^{13}$ Successful curricula include videos and group sessions that incorporate multiple interactive learning tools to develop knowledge and decision-making skills. $^{13,14}$ In 2002 the ThinkFirst Foundation of Canada developed a unit of study aimed at students in Grades 7 and 8 incorporating many of the above elements. The effectiveness of this curriculum on students' knowledge, decision-making skills, and behaviours remains unclear.

The objective of this work was to test the effectiveness of ThinkFirst For Kids at increasing specific knowledge regarding brain and spinal cord injury and injury prevention among students in Grades 7 and 8. This will extend on previous work in the field by also evaluating retention and persistence of the learned knowledge with a second post-intervention test administered in a delayed fashion. The secondary goal was to evaluate the experiences of teachers in Grades 7 and 8, via questionnaire, in implementing this program.

\section{METHODS}

\section{TFFK curriculum}

The ThinkFirst For Kids curriculum for students in Grades 7 and 8 contains six modules complying with the Ontario Provincial Health and Physical Education requirements on healthy living, growth and development, personal safety and injury prevention, substance use and abuse, risk assessment, and stress and conflict management. This curriculum, termed "Navigators" and typically administered over six weeks, instructs on risky behaviours; the brain and spinal cord; the effects of hazardous substances, actions, and venues; dangerous situations, decision-making, and stress management; and independent research. This pilot study used a mixed methods approach design that incorporated both quantitative and qualitative evaluations of the program.

\section{Teacher and Student Recruitment}

Teachers and students were recruited from a board of education in Ontario through interaction at a monthly principals meeting. Four schools were included in this work, and teachers agreeing to participate in this program were then contacted to administer the ThinkFirst for Kids curriculum. Students were asked to complete pre-intervention and, depending on curriculum timing, one or two post-intervention tests of brain and spinal cord injury knowledge. Parental consent was required for student participation in curriculum instruction and testing. Compensation to teachers was in the form of a bookstore giftcard and to students in the form of cinema tickets.

\section{Quantitative}

A non-identifying, self-report questionnaire was used to obtain information about student demographics and measure general knowledge of the topics covered in the curriculum document. The questionnaire was pilot-tested on a class of Grade 7 students, and revisions to the items and the wording of the directions were made. Demographic items on the questionnaire included data about grade, gender, age, previous instruction about brain and spinal cord injuries, and acquaintances with people with such injuries. Specific knowledge questions were in a true/false format (Appendix A), simulating situations where quick decisions might be required. Nineteen of the 30 questions were based on material that the students were expected to have learned either through instruction in previous grades, parental instruction, or media. The remaining 11 items were based on new topics introduced in the program. A sample question was "Brain cells can grow back if they are damaged." Scores on this 30-item true/false test were compared before (Form A), after (Form B), and six weeks following the curriculum (Form C). This permitted evaluation of prior knowledge, immediate impact of instruction, and longer-term retention of information. All forms contained the same demographic questions in the same sequence, with knowledge testing questions same in content but different in sequence. The number of correct answers on each test was recorded out of 30, with two schools administering the pre-test and two post-tests and two schools only administering the pretest and one post-test.

\section{Qualitative}

Following administration of the knowledge questionnaires, teachers and students were then also interviewed when timing and availability permitted. Further information about the practicalities of curriculum instruction were obtained from audio-taped teacher interviews of all involved teachers (Appendix B), with a sample question being "Which lessons seemed to go well? Why?" Focus group discussion with students also helped determine attitudes towards the curriculum and behaviours after receiving the instruction with only two schools able to participate (Appendix B), with a sample question being "When a group of your friends wants to do an activity that you 
think may not be safe, what do you do?" These groups consisted of 8 and 12 students each, lasting approximately 30 minutes, and audio-taped.

\section{Data Analysis}

Each test questionnaire was graded as the absolute number of correct responses out of 30 questions, with individual school and overall scores reported by mean and standard deviation. Twofactor analysis of variance (ANOVA) with post-hoc Dunn's analysis was utilized to determine the effects of school and timing of evaluation on student questionnaire scores. Assessment of an interaction effect between these two factors will provide insight into whether certain schools or populations of students are more likely to benefit or not from this mechanism of instruction.

Further evaluation involved examining the proportion of students who were able to achieve scores of at least 27 out of 30 $(90 \%)$ correct responses. Differences in this categorical variable by timing of evaluation were tested by $\chi^{2}$ analysis. Eleven of the 30 administered questions were assessed as reflecting curriculum-specific knowledge for which the students were specifically instructed. These questions were subjected to further analysis involving two-factor ANOVA with post-hoc Dunn's analysis to test for the differences in accrual and retention of information by school and by test timing. Response heterogeneity was tested by timing of evaluation using the Brown-Forsythe test to understand if disparity of knowledge among students before learning the curriculum was decreased after the teaching. Statistical analyses were performed at the 0.05 level of significance.

Qualitative responses were grouped according to question, with data coded into broad categories and further organized into sub-categories. A sample category was hands-on activities and one of its sub-categories was the signal and letter code activity. ${ }^{15,16}$ When coding, significant text was highlighted, notes were taken, and comments were written in the margins of the transcripts. Interpretations were made using inductive reasoning. ${ }^{17,18}$ The trustworthiness indicators used in this study were credibility and confirmability. Credibility was established by having the participants review interview transcripts to ensure accuracy. ${ }^{19}$ A confirmability audit was tested by ensuring that interview findings emerging from coding could be traced back to the database. ${ }^{20}$

\section{RESULTS}

\section{Quantitative}

Scored questionnaires were obtained from 204 students at all four schools before intervention, from 176 students at all four schools early after intervention, and 111 students at two schools late after intervention. Scores are summarized in the Table, illustrating mean and standard error for questionnaire responses stratified by school and timing of evaluation. Significant differences in pre-intervention scores were noted both among schools (Figure 1, ANOVA, p < 0.01) and for a given school based on timing of evaluation (Dunn's test, $\alpha=0.05$ ). The knowledge gain seems durable over short and long terms, with average improvement among the four schools of $1.1 \pm 0.3$ correct responses $(3.6 \pm 1.0 \%)$ on evaluation early after teaching, with further gain of $0.58 \pm 0.13$ correct responses $(1.9 \pm 0.4 \%)$ on late evaluation (Figure 2, ANOVA, $\mathrm{p}<0.01$ ). There was no interaction effect for school and timing (ANOVA, $\mathrm{p}=0.69$ ) suggesting that the positive effect of the instructional curriculum was maintained across different venues.

Significant heterogeneity was noted in score variance at different time points (Brown-Forsythe, $\mathrm{p}<0.01$ ). The mean absolute difference from the median before teaching was $1.82 / 30$, dropping to $1.49 / 30$ early after the instruction and $0.99 / 30$ late after the instruction, suggesting that knowledge about head injury and outcomes is both increased and made more consistent among students by the curriculum.

Baseline knowledge about this subject is prevalent among Grade 7 and Grade 8 students, with a preponderance of high scores among all test sessions. Prior to instruction, $60 \%$ of respondents achieved scores of at least 27 of 30 correct responses. At early and late evaluations after the intervention, $79 \%$, and $90 \%$ achieved such high scores, reflecting again that while there is some knowledge of students achieving at least 27 of 30 responses correct before, early after, and late after the intervention (Figure 3).

The 11 questions that tested curriculum-specific information revealed dichotomous results. Among five questions for which more than $90 \%$ of students scored correctly in the pre-instruction evaluation, non-significant trends toward improved scoring were observed in early and late post-instruction evaluation (ANOVA, $\alpha=0.05$ ). Conversely, among all six questions for which fewer

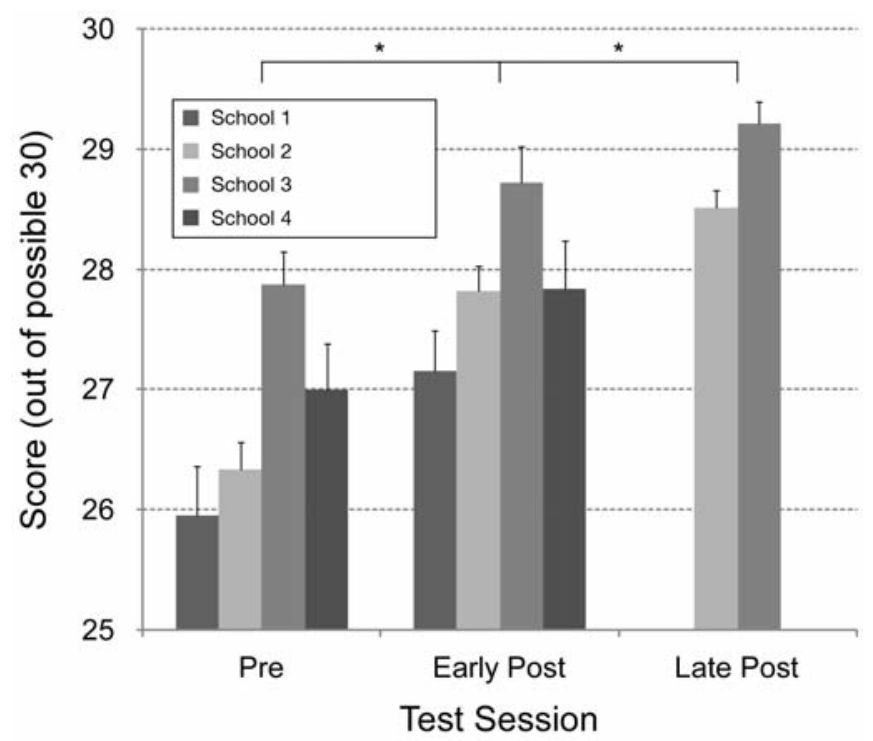

Figure 1: Questionnaire scores stratified by school and timing of test, illustrated as mean \pm s.e.m. Significant intervention effects were noted with progressively higher scores from before administration of the curriculum to early and late post-intervention evaluations (ANOVA, $p<$ 0.01). While score differences were also observed between schools (ANOVA, $p<0.01$ ), no interaction effect occurred suggesting widespread and equivalent benefit of the intervention across the four schools (ANOVA, $p=0.69$ ). 
Table: Student questionnaire scores stratified by school and timing of evaluation

\begin{tabular}{clll}
\hline School \# & Test A & Test B & Test C \\
\hline $\mathbf{1}$ & $26.0 \pm 0.4(45)$ & $27.2 \pm 0.3(45)$ & N/A \\
$\mathbf{2}$ & $26.3 \pm 0.2(121)$ & $27.8 \pm 0.2(98)$ & $28.5 \pm 0.2(87)$ \\
$\mathbf{3}$ & $27.9 \pm 0.3(24)$ & $28.7 \pm 0.3(21)$ & $29.2 \pm 0.2(24)$ \\
$\mathbf{4}$ & $27.0 \pm 0.4(14)$ & $27.8 \pm 0.4(12)$ & N/A \\
Overall & $26.48 \pm 0.17(204)$ & $27.75 \pm 0.16 *(176)$ & $28.65 \pm 0.13 * * *(111)$ \\
\hline
\end{tabular}

Scores are stratified by school and test timing, pre-intervention (A) and early (B) and late (C) post-

intervention. Scores are presented as mean \pm s.e.m., with the number of responses stated in parentheses. * significantly greater than Test $\mathrm{A}$, ** significantly greater than Test $\mathrm{B}$, at the 0.05 level of significance.

than $90 \%$ of students scored correctly in the pre-instruction evaluation, improvement in scoring was observed in five questions at post-instruction evaluations with retention of that knowledge among those administered the late post-instruction evaluation (ANOVA, $\alpha=0.05$ ).

The impact of the intervention on decision making and behaviour was reported by students who were administered Form C. Of these 111 students, $70 \%$ reported that their decision making had changed when confronted with situations involving risky behaviours and $71 \%$ indicated that their behaviours had changed.

\section{Qualitative}

\section{Teachers}

Teachers unanimously reported the ThinkFirst for Kids curriculum to be effective in conveying information to students about brain and spinal cord injuries with lessons that were convenient to use. While all were able to complete the instructive Lessons 1 through 5, the personal research Lesson 6 was only filled by one teacher due to time constraints in the other schools. Nevertheless, all teachers planned to use the curriculum with future students, with positive comments including "There are good activities that I will be taking out and using again." Two teachers also reported that students had proclaimed themselves to be more aware of the severity of the long-term outcomes of acting without thinking. One criticism was that certain questionnaire items may have had answers that were obvious, though follow-up comments included that the purpose of the test was to assess if students understood the fundamentals about brain and spinal cord injuries and personal safety.

\section{Students}

Many students knew someone who had sustained a brain or spinal cord injury from skiing, diving, snowboarding, or jumping. This knowledge of injury severity was self-reported to affect the perception of the instructed curriculum, although many still felt that the video component helped further increase understanding of the long-term outcomes of risky activities. Of further surprise to many students included the absolute numbers of people suffering brain and spinal cord injury on an annual basis, with typical comments including those numbers to be "a lot bigger than I would have thought." Other effective strategies included hands-on and creative activities such as composing rap songs, with little expressed enthusiasm for worksheets. Focus groups comments included: "We're not made of steel. We can break so easily."

Despite instruction on brain and spinal cord injuries, students inconsistently reported following bike safety rules. Only one

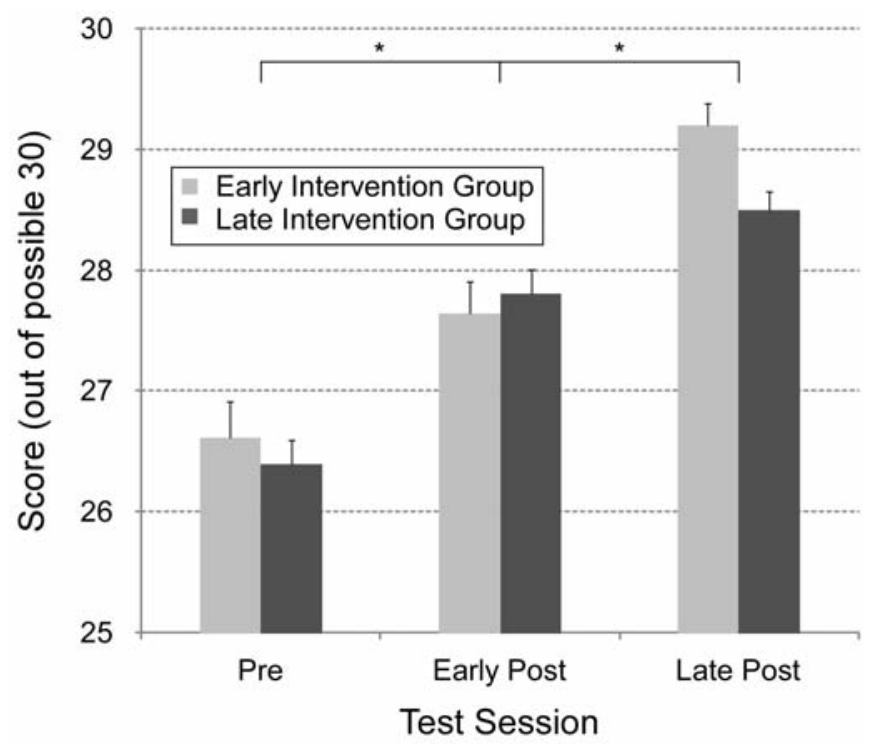

Figure 2: Overall questionnaire scores stratified by timing of test, illustrated as mean \pm s.e.m.. A significant effect of test timing is observed (ANOVA, $p<0.01)$ from pre-intervention to both early and late postintervention, suggesting both retention and perhaps further consolidation of the instruction over time (Dunn's $\alpha=0.05$ ). 


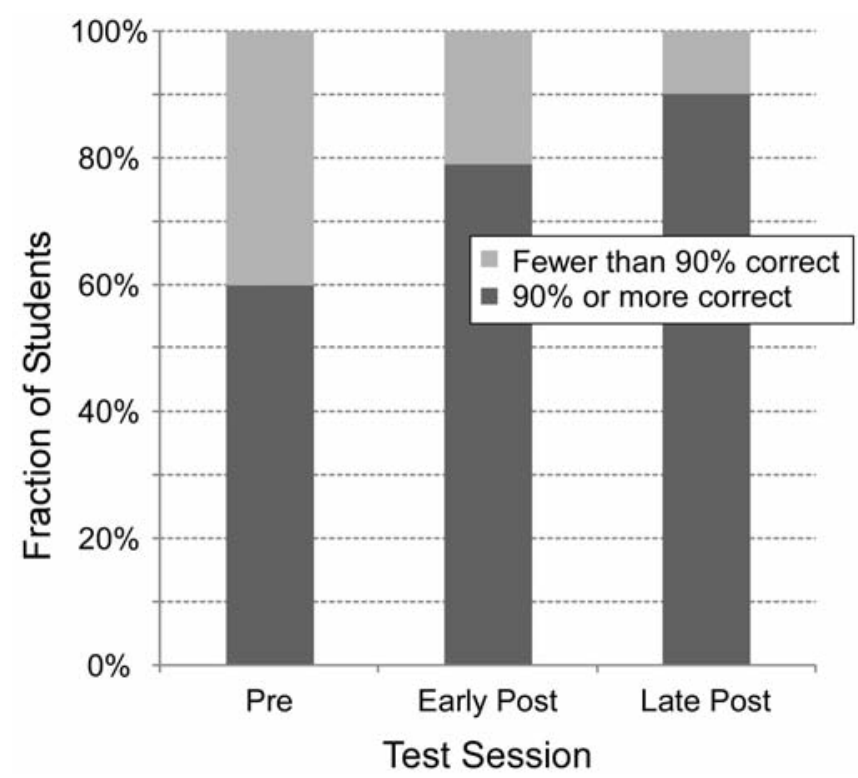

Figure 3: Fraction of all students who score at least $90 \%$ on the questionnaire (minimum 27 of 30 correct responses), stratified by timing of test. A significant intervention effect was noted with $60 \%$ of students achieving such a score before the head injury curriculum was taught, and $79 \%$ and $90 \%$ achieving such a score early and late after the teaching $\left(\chi^{2}\right.$ test, $\left.p<0.01\right)$.

student knew hand signals, only wearing a helmet for longer distances and on busy streets. By contrast, when asked how they would react when a friend asked them to engage in a dangerous behaviour, many students stated that they would decline with an assertive response as taught in Lesson 5, such as "No, but you go ahead." These statements are examples of an assertive response to peer pressure that was learned in Lesson 5. Passive responses to peer pressure included stalling decision to participate when in a group, with decisions to let friends go first and assess the outcomes. It is unclear whether these strategies for managing peer pressure were now or previously learned, but they were actively reinforced as appropriate through class discussions.

\section{DisCUSSION}

These results clearly support previous work stating students were able to retain basic information on safety, ${ }^{14}$ presumably accumulated over the years through repeated didactic and informal exposure in youth. Further results of this work show that new information on brain and spinal cord injuries was retained immediately after exposure to the intervention, which supports the results of previous research. ${ }^{9,12}$ This study extends previous work by also demonstrating the longer term knowledge retention by providing a second post-intervention test in a delayed fashion. Indeed, the apparent increase in knowledge between the first and second post-intervention evaluations is unexpected. There are many possible reasons for this observation that include intellectual stimulation of the children to seek further knowledge after the curriculum and testing was completed, consolidation of knowledge by continued discussion among peer groups, or that only two schools completed the second test and that students at those two may have outperformed their peers. The latter possibility is supported by the significant heterogeneity of pre-intervention scores between the different schools. It is possible that students' personal connection with people who had brain and spinal cord injury, the emotional impact of the video, and the hands-on activities may have contributed to students' attending to the instruction, even though they knew the tests would not affect any of their grades. ${ }^{13}$

An assumption of any such intervention is that adolescents will take measures to protect themselves upon learning of longterm negative outcomes. However, such knowledge does not always influence behaviour with students revealing in the focus group inconsistent bicycle helmet use despite knowledge of the health implications and legislated requirements in Ontario. Berg and Westerling ${ }^{21}$ posit a strong association between parental involvement and helmet use attitudes, with influence decreasing among older children. Nevertheless, this work suggests that in addition to retaining the instructed knowledge, students' understanding of risky decisions had matured. They are presumably better able to assess risk of long-term harm and act more cautiously, although the nature of the change is unclear. From our work, however, one must thus be cautious that this increase in knowledge may not translate into altered behavior, with other social and economic forces applied by both families and peers also having substantial influence on child activity and decision-making. Further study is required, often occurring after widespread educational intervention or legislation, to evaluate any ultimately protective effect against incidence and severity of head injury.

Teachers generally found the curriculum document convenient to use and remained committed to instructing students on the prevention of brain and spinal cord injuries. It was also shown that the TFFK lessons may be used as a standalone package or may be taught as part of the Grade 8 science curriculum. Additionally, the lessons may be taught over several months or in a short period of time without affecting students' knowledge retention.

There are two barriers to moving forward from pilot to more widespread curriculum assessment. Recruitment of schools was difficult, and only four school principals elected to participate in the work. Further, students may not be again tested from the same board of education, with most of the schools, regardless of participation in this work, have begun implementing this curriculum. This may be addressed by recruiting schools from alternate boards in the same city or expanding the scope to the provincial level. The teachers may not have the time to implement this curriculum, with the requisite pre-test, instruction, and sequential post-tests. This may be addressed by recruiting in the spring and having all schools initiate the process with students early in the next academic year.

\section{Limitations}

A limitation of this questionnaire is the preponderance of high scores among all test sessions, with $60 \%, 79 \%$, and $90 \%$ of students achieving at least 27 of 30 responses correct before, early after, and late after the intervention. Clustering of results near the maximum attainable score suggests a ceiling effect that 
underestimates the actual potential intervention effect under conditions where little knowledge exists prior to instruction of the curriculum. Such effects may inflate Type I error by decreasing post-test score variability, but also to inflate Type II error by limiting the extent of observed effect. At this point, the clinical significance of improving the score performance by only several points remains in question. The ceiling effect may mask the actual potential of such curricula, with future questionnaire development planned to include sufficiently challenging evaluations so robust intervention effects may be tested and hopefully observed. The specific test questions, while not formally validated, reflected information contained within the TFFK Navigators curriculum that was taught to the students. Further, the qualitative interview questions pertained to understanding both student and teacher experiences with head injury prior to the educational intervention, and then also the ease with which this curriculum was integrated into the classroom.

This ceiling effect was further exemplified when subanalysis was performed on the curriculum-specific questions, with improved scoring observed for all questions in which few students scored correctly at the pre-instruction evaluation, but no observed effect among those questions in which more than $90 \%$ of student scored correctly at the pre-instruction evaluation. While a limitation of the questionnaire, such findings reflect that administration of such a curriculum does lead to accrual and retention of knowledge with which the students were unfamiliar to begin with.

Lastly, all four schools in this study represented a local sampling of Grade 7 and 8 classrooms from a single school board. The generalizability of the results is hence uncertain, alongside any conclusion about the utility of this intervention for improving knowledge and altering behaviour across a broad socioeconomic range. Further investigation into such curricula at this and other grade levels would benefit from a larger sample of schools spanning broader range of socioeconomic environments.

In conclusion, unintentional injury among children represents a public health concern in Canada with heavy burden on the healthcare system. The majority of these injuries are preventable with intervention programs offering an effective and inexpensive means to diminish the number of head injuries in children. The ThinkFirst For Kids Navigator's curriculum, developed for the Grade 7 and 8 students, was evaluated in four schools in Ottawa and found to be effective using both quantitative and qualitative outcomes. Administration of the Navigator's program not only increased knowledge, but this knowledge was retained and associated with self-reported changes in student attitudes and behaviours towards injury prevention. The translation of such knowledge into protective behaviour and reduced incidence of head injury remains an exciting opportunity to extend this work. The study identified that most students have knowledge about injury prevention but are not necessarily applying this knowledge when confronted with risk taking situations.

\section{ACKNOWLEDGEMENTS}

This project was supported by a grant provided by the ThinkFirst Foundation of Canada that was managed by the Children's Hospital of Eastern Ontario Research Institute. This included payments to graduate student (S.O.), photocopying costs, and purchase of movie passes for the participating students and gift cards for the teachers. Scientific peer review was obtained from Dr. Michael Cusimano, Dr. Charles Tator, Dr. Marielle Simon, and Dr. Brad Cousins. Research Ethics Board approval was obtained from: 1) Children's Hospital of Eastern Ontario, 2) University of Ottawa, and 3) Ottawa Carleton District School Board. The authors thank Principal Amber Skillings-Nicholson who assisted with increasing the awareness of the research project amongst the principals of the Ottawa Carleton District School Board.

\section{ApPendix A}

ThinkFirst For Kids, Grades 7 and 8 Form A

\section{Part 1}

Directions: Either circle the correct response or fill in the blank with the correct answer.

1. What is your grade? Grade 7 Grade 8

2. What is your gender? Female Male

3. What is your age? years

4. Have you been taught in another grade about safety? Yes No

5. If yes, in which grade(s) did you learn about safety?

6. Have you or someone else you know had a brain or spinal cord injury? (Brain injury includes a concussion, which is an injury to the brain as a result of being hit in the head, shaken, or spun around.) Yes No

\section{Part 2}

1. Most accidents can be prevented. T F

2. Brain injury may result in permanent problems with speech, vision, behaviour, and how the brain works. T F

3. When in a car, seat belts only have to be worn on longer trips.

T F

4. When biking, always wear a bicycle helmet that is approved by the CSA (Canadian Standards Association) and fits properly. T F

5. Cyclists do not have to obey all traffic laws for vehicles (stop at stop signs and lights; obey all traffic signs and signals). T F

6. A bicycle is the right size when the rider can touch both feet on the ground.

T F

7. A helmet and other protective gear should be worn when roller-blading, playing hockey, snowboarding, or when playing other sports.

T F

8. There is no need to check the depth of the water before diving in for the first time. If you can't see the bottom, it must be all right.

T F

9. There is no need to wear a personal flotation device (sometimes called a PFD) while in a boat and close to the shore.

T F 
10. Children under 12 can safely sit in the front seat of a car. $T \quad F$

11. A person should refuse to drive with someone who has used alcohol or drugs.

$T \quad F$

12. As long as the bus driver is visible, it is all right to cross in front of a bus.

T F

13. On playgrounds, a person should stay clear of moving swings, seesaws, and children swinging on monkey bars.

T F

14. A person should always look both ways before crossing the street.

T F

15. If a child or adolescent finds a weapon, he or she should stop, not touch it, leave the area, and call an adult. T F

16. Young children can safely use latex balloons without supervision.

T F

17. When holding a young baby, support its head. T $F$

18. If there are no cars coming, it is safe to toboggan onto a street.

T F

19. When just beginning a new job, a person should do whatever the boss says.

T F

20. A person needs to know the difference between a smart risk and a stupid risk.

$T \quad F$

21. It is alright to give a baby just a little shake to make it stop crying. T F

22. The major parts of the brain are the cerebrum, the cerebellum, and the brain stem. T F

23. Brain damage can occur in 4 minutes without oxygen. T F

24. Damaged nerve cells in the spinal cord can grow back. $T \quad F$

25. If the spinal cord is injured, a person could have pain, loss of movement of the arms and legs, or die. T F

26. Messages are sent between brain cells through neurotransmitters.

T F

27. Inhaling hazardous chemicals will not damage brain cells. T F

28. A person's skull is about $2 \mathrm{~mm}$ thick.

$T \quad F$

29. Brain cells can grow back if they are damaged. T F

30. A result of a poor decision could be a brain or spinal cord injury.

T F

\section{Part 3}

We would like to know about your ideas on this questionnaire.

1. Were the questions easy to understand?

Yes No

2. If you answered "No", what was hard to understand?

3. Were you taught the topics covered in this questionnaire? Yes No

\section{Part 4}

If you would like to be in the group interview so that you may discuss your attitudes and experiences in choosing or not choosing to do risky activities, please complete the section below.

Name:

Your E-mail address:

\section{Appendix B}

\section{PART 1}

ThinkFirst For Kids, Teacher Individual Interview

1. For how many years have you been a teacher?

2. For how many years have you taught Gr. 7/Gr. 8?

3. Have you taught a safety and injury prevention unit before?

4. Have you used the ThinkFirst materials before?

5. Did you teach all of the lessons in the unit?

6. If not, which lessons did you omit? Why?

7. Which lessons seemed to go well? Why?

8. Which lessons did not seem to go well? Why not?

9. What suggestions for improvement of the content, materials, or teaching approaches do you have?

10. Do you know someone who has had a brain or spinal cord injury? What type of injury was it and describe the recovery process. Was there any permanent damage?

11. If yes, did this experience affected the way you taught this unit? If yes, how?

12. Before teaching the unit did you follow the safety rules discussed in the lessons?

13. After teaching the unit do you follow the safety rules?

14. If yes, which rules did you start following?

15. Why were you not following them before?

16. Do you make safety a priority in your classroom? How do you do this?

17. Is safety a priority for this school? How is this done?

18. After teaching this unit, have any of the students told you about any incidents where they used the information learned in the lessons? If yes, describe the incident(s)

\section{Part 2}

ThinkFirst For Kids, Student Focus Group

1. Do you know anyone who has a brain or spinal cord injury?

2. If yes, tell me about it. What permanent injuries did the person have?

3. Did knowing this person affect how seriously you took the information presented in this unit? If so, how did it affect you?

4. What rules or information had the most impact on you? Why? 
5. Do you always follow the safety rules? (helmet use, obey traffic laws when riding a bicycle)

6. If no, why not?

7. When a group of your friends wants to do an activity that you think may not be safe, what do you do?

8. Tell me about an incident when you had to make a decision about doing something that you did not think was safe.

9. Have you ever told someone not to do something because it wasn't safe?

10. Tell me about that incident.

11. Did the person do the act? If yes, why do you think he or she did it?

12. Does the information about brain and spinal cord injuries affect the decisions you make? If not, why not?

\section{REFERENCES}

1. Coppens NM, McCabe BM. Promoting children's use of bicycle helmets. J Pediatr Health Care. 1995;9(2):51-8.

2. Kirsch SE, Pullen N. Evaluation of a school-based education program to promote bicycle safety. Health Promot Pract. 2003;4(2):138-45.

3. Parkin PC, Spence LJ, Hu X, Kranz KE, Shortt LG, Wesson DE. Evaluation of a promotional strategy to increase bicycle helmet use by children. Pediatrics. 1993;91(4):772-7.

4. Rivara FP, Thompson DC, Thompson RS, Rogers LW, Alexander B, Felix D, et al. The Seattle children's bicycle helmet campaign: changes in helmet use and head injury admissions. Pediatrics. 1994;93(4):567-9.

5. Wood T, Milne P. Head injuries to pedal cyclists and the promotion of helmet use in Victoria, Australia. Accid Anal Prev. 1988;20 (3): $177-85$

6. CIHI. Head injuries in Canada: a decade of change (1994-5 to 20034). In: Information CIfH, editor. Ottawa; 2006.

7. Azeredo R, Stephens-Stidham S. Design and implementation of injury prevention curricula for elementary schools: lessons learned. Inj Prev. 2003;9(3):274-8.
8. Bandura A. Social learning theory. Englewood Cliffs: Prentice Hall; 1977.

9. Cusimano MD, Sharman ARC, Chipman M, Freedman B, Tator $\mathrm{CH}$. Injury prevention in the community: an evaluation of the Think First for Kids program. Can J Neurol Sci. 2000;27(S2):22.

10. Greene A, Barnett P, Crossen J, Sexton G, Ruzicka P, Neuwelt E. Evaluation of the THINK FIRST For KIDS injury prevention curriculum for primary students. Inj Prev. 2002;8(3):257-8.

11. Gresham LS, Zirkle DL, Tolchin S, Jones C, Maroufi A, Miranda J. Partnering for injury prevention: evaluation of a curriculumbased intervention program among elementary school children. J Pediatr Nurs. 2001;16(2):79-87.

12. Wesner ML. An evaluation of Think First Saskatchewan: a head and spinal cord injury prevention program. Can J Public Health. 2003;94(2):115-20.

13. McGrath B. Group interventions for the prevention of injuries in young children: a systematic review. Inj Prev. 2005;11:143-7.

14. Bryer F, Grimbeek P. Can a didactic intervention influence adolescent attitudes to acquired brain injury? Educating: Weaving Research into Practice. Proceedings of the International Conference on Cognition, Language, and Special Education Research. 2004;3:167-77.

15. Krueger R, Casey M. Focus groups: a practical guide for applied research. Thousand Oaks: Sage Publications; 2000.

16. Marshall C, Rossman GB. Designing qualitative research. 4th ed. Thousands Oaks: Sage Publications; 2006.

17. Miles MB, Huberman AM. Qualitative data analysis : an expanded sourcebook. 2nd ed. Thousand Oaks: Sage Publications; 1994.

18. Patton MQ. Qualitative research \& evaluation methods. 3rd ed. Thousand Oaks: Sage Publications; 2002.

19. Guba EG, Lincoln YS. Fourth generation evaluation. Thousand Oaks: Sage Publications; 1989.

20. Mertens DM. Research and evaluation in education and psychology. 2nd ed. Thousand Oaks: Sage Publications; 2005.

21. Berg P, Westerling R. Bicycle helmet use among schoolchldren--the influence of parental involvement and children's attitudes. Inj Prev. 2001;7(3):218-22. 